Research Article

\title{
Comparison of Different Hydrocolloids on the Novel Development of Muffins from "Purple Yam" (Dioscorea alata) Flour in Sensory, Textural, and Nutritional Aspects
}

\author{
Dewni Gunasekara $\mathbb{D}^{1},{ }^{1,2}$ Ashani Bulathgama $\mathbb{D}^{1},{ }^{1}$ and Indira Wickramasinghe $\mathbb{D}^{1}$ \\ ${ }^{1}$ Department of Food Science and Technology, Faculty of Applied Sciences, University of Sri Jayewardenepura, Nugegoda, Sri Lanka \\ ${ }^{2}$ School of Science, RMIT University, Melbourne, Australia \\ Correspondence should be addressed to Indira Wickramasinghe; indiraw@sjp.ac.lk
}

Received 6 March 2021; Revised 29 June 2021; Accepted 18 August 2021; Published 16 October 2021

Academic Editor: Karthik Pothiyappan

Copyright ( $) 2021$ Dewni Gunasekara et al. This is an open access article distributed under the Creative Commons Attribution License, which permits unrestricted use, distribution, and reproduction in any medium, provided the original work is properly cited.

\begin{abstract}
Hydrocolloids can act as gluten substitutes to form the structural equivalents of the gluten network in gluten-free bakery products. "Purple yam" (Dioscorea alata) is one of the underutilized yams in Sri Lanka with high nutritional potential. The overall objective of this study was to develop gluten-free muffins using "Purple yam" (Dioscorea alata) flour with hydrocolloids (pectin, xanthan gum, and guar gum) and investigate the nutritional composition and selected properties of the muffins. The texture profiles of gluten-free muffins were analyzed through the following parameters: hardness, adhesiveness, cohesiveness, etc. The chromameter values were obtained and sensory evaluations for gluten-free muffins were carried out. The highest moisture content was recorded in pectin-incorporated muffins $(17.70 \pm 0.50 \%)$. The protein content of all three types of muffins was around $5 \%$. The highest fat content was recorded in pectin-incorporated muffins $(19.26 \pm 0.51 \%)$. The ash content of all three types of muffins was around $2 \%$. Potassium was the most predominant element found in each muffin. The hardness of guar gum-incorporated muffin $(6379.3 \pm 135.9 \mathrm{~g})$ was greater than that of the pectin-incorporated one $(6082.3 \pm 23.4 \mathrm{~g})$. Xanthan gum-incorporated muffins had significantly decreased cohesiveness $(0.19 \pm 0.04)$. The highest springiness was obtained in pectin-incorporated muffin $(37.13 \pm 1.61 \mathrm{~mm})$. The descending order of the chewiness of muffin is pectin - added $>$ xanthan gum - added > guar gum - added sample. According to the sensory evaluation, pectin-incorporated muffin was the best as it had obtained the highest sum of ranks for appearance, color, taste, after taste, and overall acceptability.
\end{abstract}

\section{Introduction}

Celiac disease is a chronic autoimmune disease that causes inflammation of the upper small intestine in genetically predisposed individuals [1]. Nowadays, it is more common in some parts of the world and it seems to be rising gradually $[2,3]$. The best treatment of celiac disease is to reduce the consumption of wheat, rye, and barley and use of a glutenfree diet $[4,5]$. Considering the important role of glutenfree products in the diet of celiac patients, the quality of these products should be carefully assessed and reviewed. There are many underutilized yam varieties in Sri Lanka with high nutritional potential [6]. Meanwhile, the edible yams belonging to the genus Dioscorea have been used as an energy source for decades [7]. With the urbanization and changing food habits, most of these underutilized yams have lost their significance. D. alata cultivars were discovered to provide medicinal benefits, including immunological activation and antihypertensive properties, in addition to their culinary value $[8,9]$. Hence, this research attempted to develop gluten-free muffins with the addition of $0.3 \%$ ( $w / w$ based on flour) of three different hydrocolloids (pectin, xanthan gum, and guar gum) based on $D$. alata flour. Dioscorea alata belongs to the Dioscoreaceae family. $D$. atropurpurea and D. sativa are some synonyms [10]. About 600 species of Dioscorea are consumed in various parts of the world [11]. Pangyuan [12] has mentioned that D. alata has medicinal properties and can be used in Ayurvedic and 
Western medicine. Purple yam is a great source of carbohydrates, fibre, and potassium and contains antioxidants including anthocyanins and vitamin C [13].

Some of the properties of bakery products such as bread and cake have unique characteristics that are comparatively difficult to replace without the gluten in the product. In recent years, several studies have identified that "hydrocolloids" can act as gluten substitutes to improve the texture, structure, and rheological properties of bakery products [14]. Hydrocolloid is a food additive that has properties that can improve the viscosity of the dough and enhance the characteristics of gluten-free bakery products [15]. For viscosity control and better processing tolerance in cake recipes, hydrocolloids are used today. The industrial-scale cake production involves high-shear mixing. The batter is normally processed through a pumping machine and continuous mixers. Hydrocolloids can control the viscosity of the batter and prevent degassing of the batter during its processing [16]. The commonly used hydrocolloids in the bakery industry are pectin, egg albumin, galactomannans, xanthan gum, Arabic gum, and guar gum [17]. Among these hydrocolloids, the impact on the characteristics of glutenfree muffins was evaluated using three different hydrocolloids including pectin, xanthan gum, and guar gum. These hydrocolloids have been used in the bakery industry for crumb softness and to improve the keeping quality during storage $[17,18]$.

Pectin is frequently extracted from citrus fruit and apples, and it can be used as a vegan substitute in glutenfree formulas. Pectin is a complex carbohydrate and it improves the structure of breads and cakes. Moreover, pectin promotes moisture retention that keeps baked products from drying out and keeps them soft. Xanthan gum is a nonabsorbing polymer that shows good thickening ability even at low concentrations, and it shows good water holding capacity $[19,20]$. A stretchy web is formed when xanthan gum is mixed with water, which is similar to gluten's structure. However, xanthan gum is more expensive. Guar gum is an effective enhancer, as it reduces the stiffness of muffins and increases the specific volume [21]. It is less expensive than xanthan gum but has incredible thickening power. The bakery products formulated with guar gum are less "gummy" than products made with xanthan gum. Both xanthan gum and guar gum have laxative properties, which can cause digestive distress in some people. In addition xanthan gum and pectin improve the softer texture, porosity, and elasticity of the crumb, as well as sensory attributes [22].

Therefore, this study is aimed at assessing the effects that hydrocolloids have on the texture profile, nutritional composition, chromameter values, and sensory attributes.

\section{Materials and Methods}

2.1. Ingredients. Fully mature, undamaged D. alata yams were collected from the Agricultural Research Station, Department of Agriculture, Telijjawila, Sri Lanka. The other ingredients used were sugar, whole egg, baking powder, sunflower oil, and milk were supplied by the Supermarkets,
Wijerama, Sri Lanka. Pectin, xanthan gum, and guar gum were obtained from the suppliers of Colombo, Sri Lanka.

2.2. Preparation of Flour Samples. D. alata yams were hand peeled, washed, and cut into thin pieces and dried in an air convection oven (MA 035 Marconi, Colombo, Sri Lanka) at $60^{\circ} \mathrm{C}$ for $24 \mathrm{~h}$. The dried pieces were powdered using a laboratory scale grinder (ABBLBL468AB, Colombo, Sri Lanka) and sifted through a $300 \mu \mathrm{m}$ sieve. The flour samples were sealed and packed in airtight containers for further preparation.

2.3. Development of Gluten-Free Muffins. The gluten-free muffins were developed according to the modified method described by Bhaduri and Navder [23].The muffin recipe was formulated with $D$. alata flour $(70 \mathrm{~g})$, sugar $(45 \mathrm{~g})$, whole egg (35 g), baking powder (3.5 g), sunflower oil (30 g), and milk $(55 \mathrm{ml})$, and muffins were prepared under four treatments. Three treatments were developed with the incorporation of three different hydrocolloids, and one treatment was developed without the addition of hydrocolloids as a control sample. Those three treatments were as follows: incorporated pectin, xanthan gum, and guar gum by $0.3 \%(w / w$ based on flour) as a replacement for gluten [24]. Also, as a comparison, muffins were prepared without the addition of any hydrocolloid percentage. The dry ingredients $D$. alata flour, baking powder, and pectin/xanthan gum/guar gum were weighed and sifted together. The whole egg, milk, sugar, and sunflower oil were mixed well, and the flour mixture was added and was mixed for $5 \mathrm{~min}$ at a speed of $240 \mathrm{rpm}$ in a multifunction food processor (Rowenta Universo 700, France); vanilla was finally added and mixed well. After scraping down the bowl, $50 \mathrm{~g}$ of batter was weighed and placed in aluminum baking molds. The muffins were baked in an oven (Indesit built-in electric oven, $2200 \mathrm{~W}$, Colombo, Sri Lanka) at $180^{\circ} \mathrm{C}$ for $30 \mathrm{~min}[25,26]$.

2.4. Proximate Analysis. The proximate analysis was carried out to determine the moisture content (AOAC 931.04), crude protein content (AOAC 920.87), total fat content (AOAC 922.06), and total ash content (AOAC 923.03) of each muffin samples [27]. The results were expressed on dry weight (DW) basis and all measurements were performed in triplicates. The determination of the mineral (potassium, calcium, iron, zinc, magnesium, and copper) content was carried out according to the AOAC official procedure 975.03 method of dry ashing followed by the atomic absorption spectroscopy method [27]. The atomic absorption spectroscopy machine used was Hitachi model 170-10, and the muffle furnace (Wisetherm, Colombo, Sri Lanka) was used to get ash samples.

2.5. Crust and Crumb Color. The surface crust and crumb color of muffins, represented by the CIE $L * a * b *$ model ( $L *$ : lightness ; $a *$ : redness $; b *$ : yellowness), were measured by using a chromameter (Lovibond ${ }^{\circledR}$ LC100, Colombo, Sri Lanka). Color values were taken as replicates $(n=3)$ in different areas of the crumb and crust on the muffin surface as suggested by Broyart et al. [28]. 
2.6. Texture Characterization. For two-cycle compression, a CT3 texture analyzer ( $50 \mathrm{~kg}$, Brookfield, USA) was used to measure the force-time curves as penetration profiles. The method for texture profile analysis was used as recommended in Brookfield's instruction manual. The texture analyzer was supplied with a load cell of $100 \mathrm{~g}$ and application software (Brookfield Texture PRO CT) [29]. Two successive compressions were carried out on each sample. The resulting force-time curves were developed for hardness, chewiness, gumminess, adhesiveness, and cohesiveness. The accessory used for all measurements was a TA11/1000 $(25.4 \mathrm{~mm}$ diameter cylinder probe, stainless steel, $10 \mathrm{~g}$ ) probe. Each sample was tested two times at the test and a return speed of $1 \mathrm{~mm} / \mathrm{sec}$ and a target depth of $2 \mathrm{~mm}$. Trigger load was $1.0 \mathrm{~g}$, the pretest speed was $2 \mathrm{~mm} / \mathrm{sec}$, and the data rate was 10 points/sec. Upon two compression cycles, the probe was automatically returned to the initial starting point and the texture analyzer was reset for the next test. All analyses were conducted at ambient temperature. The force-time deformation curves during compression and decompression cycles were obtained each time. The same textural properties were measured for all prepared samples. All results were expressed in a report with values automatically calculated by the analyzer's software $[30,31]$.

2.7. Sensory Evaluation. The three types of muffins were subjected to evaluate their appearance, color, aroma, texture, taste, after taste, and overall acceptability by 30 members of a semitrained preference test panel from the Department of Food Science and Technology, University of Sri Jayewardenepura. Panelists were informed that they would be evaluating gluten-free muffins, and they were presented with three code numbers (coded "000"). The order of presentation of the gluten-free muffins was also random. The panelists were asked to evaluate the samples according to their preferences. Samples were evaluated using a 5-point hedonic scale, with 1 for "dislike extremely" and 5 for "like extremely" [23]. They were also instructed to rank the products in the order in which they liked them, with 1 for "least liked" and 3 for "most liked." They were also asked how often they ate muffins, if they had tried gluten-free products before and if anyone in their family had celiac disease. Water and unsalted crackers were provided to panelists to cleanse their palates between samples.

2.8. Statistical Analysis. The statistical analysis of data was carried out for all experiments using ANOVA to test the significance of each variable $(a=-0.05)$ and followed by comparisons performed using the Tukey test by the statistical software MINITAB 17.

\section{Results and Discussion}

By incorporating pectin, xanthan gum, and guar gum, three types of gluten-free muffins were developed with $D$. alata flour (Figure 1). Also, as a comparison, control muffins were prepared without the addition of hydrocolloids. Images of the muffins are presented in Figure 2. The muffins developed with $100 \%$ of $D$. alata flour without the addition of any

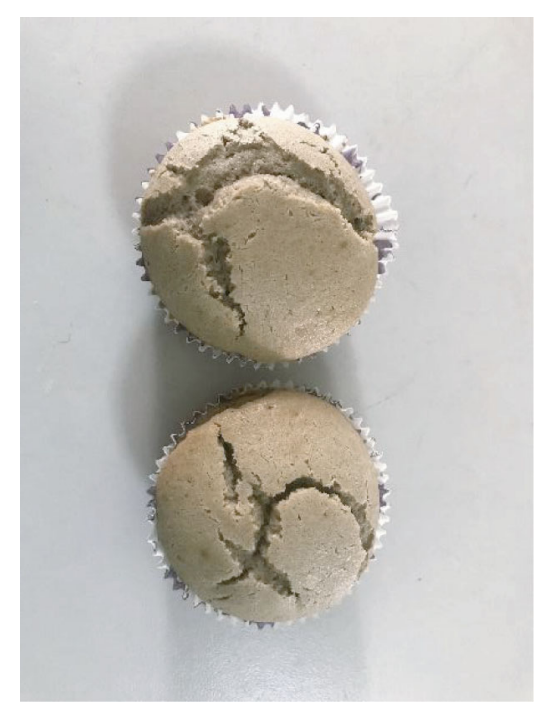

Figure 1: D. alata flour muffins without the addition of hydrocolloids.

hydrocolloid percentage that appeared in a dry and extreme tough texture and gave inedible characteristics. Also, the preparation of these muffins was hard due to the toughness of the mixture. According to Figure 2, the muffins' top was highly cracked when compared with hydrocolloidincorporated muffins. Due to the inedible characteristics showed in $D$. alata flour muffins without the addition of any hydrocolloid percentage, further analysis was only carried out with the hydrocolloid-incorporated muffins. Three types of hydrocolloid-incorporated muffins were highly appreciated by the sensory panel because they had got the characteristic taste of purple yam flour and they were similar to traditional wheat flour muffins with their appearance and soft texture.

The results obtained from the proximate analysis of three muffin samples are shown in Table 1. Some previous studies have expressed the average moisture content of muffins which is $33.0 \%$, and Lostie [32] has stated that a typical cake has a moisture content between 15 and 30\%. Therefore, a slight decrease in moisture content was observed in all treatments. The highest moisture content was recorded in pectin-incorporated muffins. It might be due to the pectin being a gelling-type hydrocolloid [33]. Furthermore, pectin has the highest water holding capacity ( $57 \mathrm{~g}$ water/g) when compared to xanthan gum and guar gum [34]. Dogan et al. [35] have identified that the water absorption capacity (WAC) of guar gum is higher than that of xanthan gum. However, some studies have evaluated that the water holding capacity of xanthan gum $(19.2 \mathrm{~g}$ water/ $100 \mathrm{~g}$ hydrocolloid) is higher than that of guar gum $(4.8 \mathrm{~g}$ water $/ 100 \mathrm{~g}$ hydrocolloid) [36]. Hydrocolloids vary their properties, due to the origin, the variety, and the lifetime of the plant if it is a plant extraction and the extraction method. Therefore, these different properties of hydrocolloids cause different values of water holding capacity. In this study, there was no significant difference in moisture content between the xanthan gum muffins and the guar gum muffins. The highest fat content was recorded in pectin-incorporated muffins 


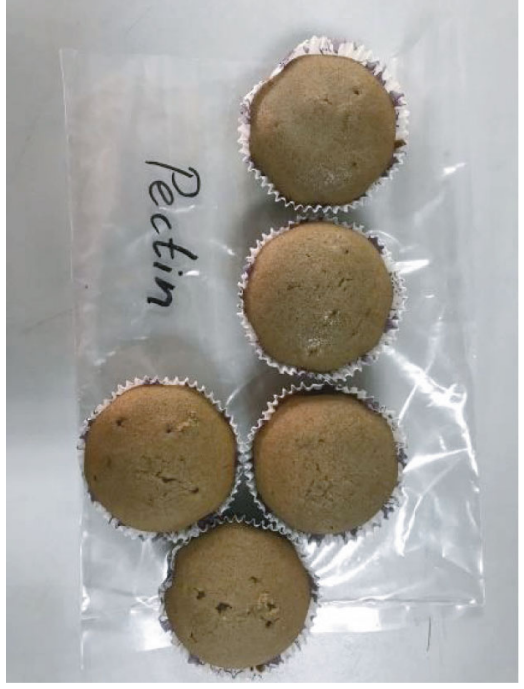

(a)

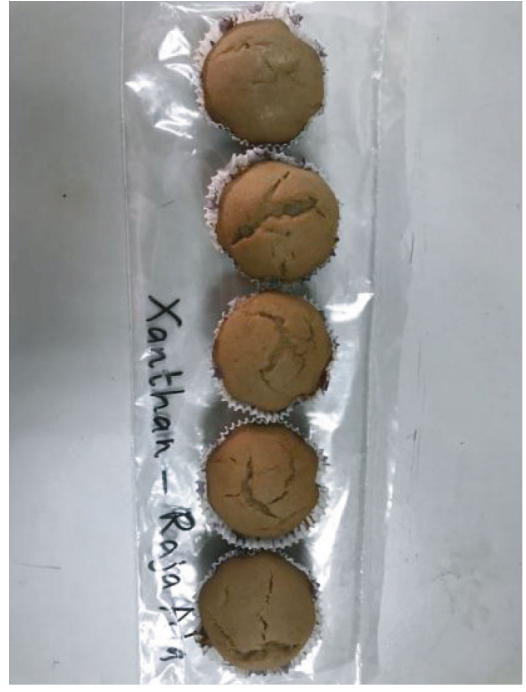

(b)

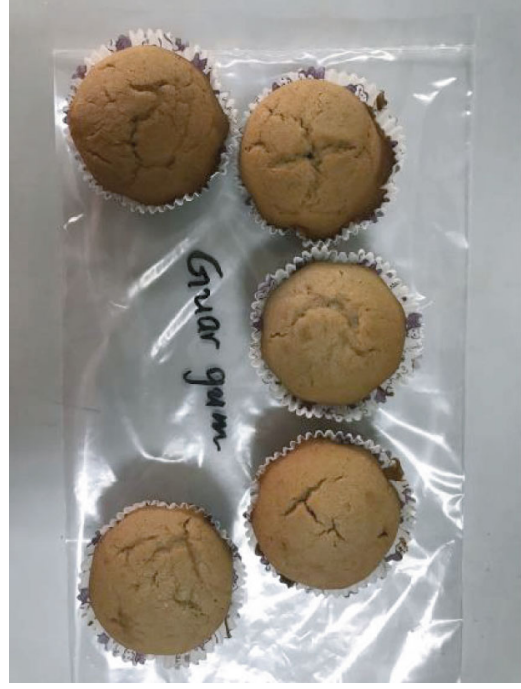

(c)

Figure 2: D. alata flour muffins. (a) Pectin-incorporated muffins. (b) Xanthan gum-incorporated muffins. (c) Guar gum-incorporated muffins.

Table 1: Nutritional composition of three different muffins.

\begin{tabular}{|c|c|c|c|}
\hline Parameters & Pectin-incorporated muffins & Xanthan gum-incorporated muffins & Guar gum-incorporated muffins \\
\hline Moisture \% & $17.70 \pm 0.50^{\mathrm{a}}$ & $14.16 \pm 0.43^{b}$ & $13.88 \pm 0.81^{b}$ \\
\hline Protein \% & $5.42 \pm 0.38^{\mathrm{a}}$ & $5.38 \pm 0.18^{\mathrm{a}}$ & $5.49 \pm 0.06^{\mathrm{a}}$ \\
\hline Fat $\%$ & $19.26 \pm 0.51^{\mathrm{a}}$ & $18.62 \pm 0.25^{\mathrm{a}}$ & $18.82 \pm 0.30^{\mathrm{a}}$ \\
\hline Ash \% & $2.07 \pm 0.04^{\mathrm{a}}$ & $2.07 \pm 0.04^{\mathrm{a}}$ & $2.11 \pm 0.04^{\mathrm{a}}$ \\
\hline $\mathrm{K}$ & $431.55 \pm 6.84^{\mathrm{a}}$ & $451.68 \pm 15.02^{\mathrm{a}}$ & $419.326 .3^{\mathrm{a}}$ \\
\hline $\mathrm{Mg}$ & $35.61 \pm 1.54^{\mathrm{b}}$ & $49.51 \pm 0.54^{\mathrm{a}}$ & $50.74 \pm 0.56^{\mathrm{a}}$ \\
\hline $\mathrm{Ca}$ & $6.04 \pm 0.45^{c}$ & $7.38 \pm 0.66^{\mathrm{b}}$ & $9.14 \pm 0.31^{\mathrm{a}}$ \\
\hline $\mathrm{Zn}$ & $1.01 \pm 0.03^{\mathrm{a}}$ & $1.16 \pm 0.04^{\mathrm{a}}$ & $1.18 \pm 0.11^{\mathrm{a}}$ \\
\hline $\mathrm{Cu}$ & $0.41 \pm 0.01^{\mathrm{b}}$ & $0.458 \pm 0.01^{\mathrm{a}}$ & $0.43 \pm 0.01^{\mathrm{b}}$ \\
\hline $\mathrm{Fe}$ & $0.93 \pm 0.06^{\mathrm{a}}$ & $1.04 \pm 0.04^{\mathrm{a}}$ & $1.01 \pm 0.05^{\mathrm{a}}$ \\
\hline
\end{tabular}

Values in the same row with different superscripts indicate significant difference $(P<0.05)$.

$(19.26 \pm 0.51 \%)$, and the lowest was recorded in xanthan gum-incorporated muffins $(18.62 \pm 0.25)$. The fat content did not show any significant difference between the three types of muffin samples $(p<0.05)$. The protein content of the three types of muffins ranged from $5.38 \%$ to $5.49 \%$, and the total ash content was around $2 \%$. There was no significantly different protein and ash content between all muffin samples according to the one-way ANOVA Tukey pairwise comparison test at a 0.05 significance level. Potassium $(\mathrm{K})$ was the most predominant element found in each muffin. Also, the main mineral in purple yam is potassium (K). $100 \mathrm{~g}$ of cooked purple yam provides $13.5 \%$ of the daily value (DV) of potassium [37].

The color values $(L, a *$, and $b *)$ of the crumb and crust of muffins were given in Table 2, and for the $a *$ value, a negative value indicates the closeness to green and a positive value indicates the closeness to red color [38]. Additionally, a negative $b *$ value indicates the closeness to blue and a pos- itive value indicates the closeness to the yellow color as all products only show positive values and $b *>a *$ indicates that all products are closer to the yellow color. The lightness of the crumb of the muffin which was prepared by incorporating xanthan gum has significantly the highest lightness when compared with the other two muffins' crumbs. The crumb of the pectin-incorporated sample has the significantly lowest lightness. The surface crust color is one of the critical quality attributes, because it is directly responsible for the initial consumer's acceptance [39]. The crust color is a result of browning reactions: combined Maillard reaction and sugar caramelization. When the surface temperature reaches $100^{\circ} \mathrm{C}$, browning reactions are initiated, and then, the crust turns darker [28].

There was not a significant difference between the crust of xanthan gum-incorporated muffin and the crust of guar gum-incorporated muffin. The crust of the pectinincorporated muffin has shown the highest darkness. The 
TABLE 2: Average chromameter values for three different muffins.

\begin{tabular}{|c|c|c|c|c|}
\hline Muffin variety & & $L *$ & $a *$ & $b *$ \\
\hline \multirow{2}{*}{ Pectin incorporated muffin } & Crumb & $35.93 \pm 0.85^{c}$ & $7.10 \pm 1.47^{\mathrm{d}}$ & $16.27 \pm 1.10^{\mathrm{a}}$ \\
\hline & Crust & $37.30 \pm 0.20^{\mathrm{e}}$ & $08.40 \pm 0.92^{c}$ & $16.70 \pm 1.49^{\mathrm{b}}$ \\
\hline \multirow{2}{*}{ Xanthan gum incorporated muffin } & Crumb & $48.50 \pm 0.30^{\mathrm{b}}$ & $6.97 \pm 0.12^{\mathrm{d}}$ & $18.33 \pm 1.23^{\mathrm{a}}$ \\
\hline & Crust & $38.70 \pm 0.27^{\mathrm{d}}$ & $11.50 \pm 0.99^{\mathrm{b}}$ & $17.07 \pm 5.25^{\mathrm{b}}$ \\
\hline \multirow{2}{*}{ Guar gum incorporated muffin } & Crumb & $45.40 \pm 0.20^{\mathrm{a}}$ & $6.13 \pm 1.27^{\mathrm{d}}$ & $18.07 \pm 0.76^{\mathrm{a}}$ \\
\hline & Crust & $39.30 \pm 0.61^{\mathrm{d}}$ & $14.10 \pm 0.44^{\mathrm{a}}$ & $19.63 \pm 8.00^{\mathrm{b}}$ \\
\hline
\end{tabular}

$\overline{\mathrm{a}, \mathrm{b}, \mathrm{c}, \mathrm{d}, \mathrm{e}}$ Values in the same column with different superscripts indicate significant differences $(p<0.05)$.

TABLE 3: Instrumental texture analysis of muffins.

\begin{tabular}{lccc}
\hline Parameters & Pectin-incorporated muffin & Xanthan gum-incorporated muffin & Guar gum-incorporated muffin \\
\hline Hardness $(\mathrm{g})$ & $6082.3 \pm 23.4^{\mathrm{c}}$ & $6963.3 \pm 130.5^{\mathrm{a}}$ & $6379.3 \pm 135.9^{\mathrm{b}}$ \\
Adhesiveness (mJ) & $11.87 \pm 0.55^{\mathrm{a}}$ & $12.80 \pm 0.70^{\mathrm{a}}$ & $12.37 \pm 0.06^{\mathrm{a}}$ \\
Cohesiveness & $0.35 \pm 0.04^{\mathrm{a}}$ & $0.19 \pm 0.04^{\mathrm{b}}$ & $0.25 \pm 0.04^{\mathrm{b}}$ \\
Springiness (mm) & $37.13 \pm 1.61^{\mathrm{a}}$ & $29.76 \pm 0.60^{\mathrm{b}}$ & $24.39 \pm 1.92^{\mathrm{c}}$ \\
Gumminess (g) & $1849.3 \pm 151.7^{\mathrm{a}}$ & $975.7 \pm 97.8^{\mathrm{b}}$ & $1022.7 \pm 89.1^{\mathrm{b}}$ \\
Chewiness (m) & $657.27 \pm 16.90^{\mathrm{a}}$ & $599.9 \pm 19.2^{\mathrm{b}}$ & $583.57 \pm 14.00^{\mathrm{b}}$ \\
\hline
\end{tabular}

${ }_{\mathrm{a}, \mathrm{b}, \mathrm{c}}$ Values in the same row with different superscripts indicate a significant difference $(p<0.05)$.

$a *$ values of the crumb of all three types of muffins did not show a significant difference. In addition, the $b *$ values of both the crumb and the crust did not show a significant difference at a 0.05 significant level.

The primary texture profile analysis (TPA) parameters such as hardness, adhesiveness, springiness, and cohesiveness and secondary parameters of gumminess and chewiness are shown in Table 3. Hardness is defined as the maximum peak force during the first compression cycle (first bite); here, the highest hardness was shown in xanthan gum-incorporated muffin. The hardness of guar gum-incorporated muffin $(6379.3 \pm 135.9 \mathrm{~g})$ was greater than pectin-incorporated muffin $(6082.3 \pm 23.4 \mathrm{~g})$. Adhesiveness is the work necessary to overcome the attractive forces between the surface of the food and the surface of other materials with which the food comes into contact (e.g., tongue, teeth, and palate) [23]. Based on ANOVA instrumental texture analysis, significant differences in adhesiveness of the samples were obtained. There was no significant difference of adhesiveness between the three types of muffins at 0.05 significant level. Cohesiveness is defined as the ratio of the positive force during the second compression to that during the first compression, and this parameter is the strength of the internal bonds which make up the body of the product. Xanthan gum-incorporated muffins had significantly decreased cohesiveness $(0.19 \pm 0.04)$ compared to the other muffins, and lower compression energy was required. Typically, a more cohesive product retains more gas and has a higher volume [40]. Springiness is related to the height that the food recovers during the time that elapses between the end of the first bite and the start of the second bite. Springiness is associated with freshness in a product with a high-quality muffin having higher springiness values [41]. The highest springiness was obtained in pectin-incorporated muffin $(37.13 \pm 1.61 \mathrm{~mm})$. Moreover, xanthan gum-incorporated muffin was significantly springier than any guar gumincorporated muffins. There was no significant difference in the gumminess of the xanthan and guar gum muffins. The decreasing order of chewiness of muffin is pectin - added $>$ xanthan gum - added $>$ guar gum - added sample.

A sensory evaluation was carried out to identify the consumer acceptability of the muffins and to select the best suitable hydrocolloid for $D$. alata muffins. The effect of the sensory properties such as appearance, color, aroma, texture, taste, after taste, and overall acceptability was evaluated among the three different muffins. Nonparametric data obtained from this sensory evaluation were statistically analyzed by using the Friedman test at a 95\% confidence level. The mean separations were done by using the Friedman test at a $95 \%$ confidence level. The three samples were named as sample number 319: xanthan gum-incorporated muffin, sample number 482: pectin-incorporated muffin, and sample number 593: guar gum-incorporated muffin.

The sensory characteristics of gluten-free muffins depend on the number and variety of hydrocolloids used as a gluten substitute, as this influences the interaction between them and starch, which is the key ingredient in the dough [42]. The web diagram for the sensory evaluation of the three muffin samples is shown in Figure 3. According to the sensory evaluation, pectin-incorporated muffin was the best as it had obtained the highest sum of ranks for appearance, color, taste, after taste, and overall acceptability. Furthermore, pectin-incorporated muffins had obtained a medium sum of ranking values of aroma and texture. Pectin is a complex carbohydrate used to thicken jams and jellies. 


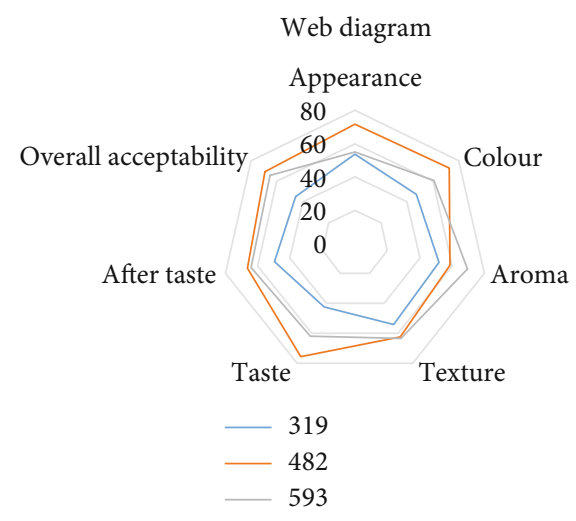

FIGURE 3: Web diagram for the sensory evaluation of the three muffin samples.

Dried pectin, which can be difficult to find, helps provide structure for breads and cakes [43]. It absorbs moisture, which helps keep baked goods from drying out and keeps them soft [44]. Therefore, it can be concluded that muffins are very soft products and because of the hygroscopic ability of pectin, pectin-incorporated muffins stayed fresher than other muffins. Moreover, pectin was obtained from a natural source: leaves of "Cylea peltata" (Kahipiththan tree). Guar gum is made from a legume plant. It is less expensive than xanthan gum but has incredible thickening power. It makes muffins that are less "gummy" than muffins made with xanthan gum. Both xanthan gum and guar gum have laxative properties, which can cause digestive distress in some people. Older gluten-free recipes relied heavily on xanthan gum [45]. Xanthan gum is made from corn. Xanthan gum is used for only a trace amount in recipes; if not, the product can become heavy or slimy [46]. Gums form a structural equivalent of a gluten network when mixed with water. However, xanthan gum is expensive and some people who are sensitive to gluten are also sensitive to xanthan gum. Some people can taste the gum in baked goods.

\section{Conclusions}

The hydrocolloids influence the moisture content of glutenfree muffins. The highest moisture content was recorded in pectin-incorporated muffins $(17.70 \pm 0.50 \%)$. Moreover, the chromameter values and texture profile of muffins varied according to different hydrocolloids. The hardness of xanthan gum-incorporated muffin $(6963.3 \pm 130.5 \mathrm{~g})$ was the highest. Xanthan gum-incorporated muffins had significantly decreased cohesiveness $(0.19 \pm 0.04)$ compared to the other muffins. The highest springiness was obtained in pectin-incorporated muffin $(37.13 \pm 1.61 \mathrm{~mm})$. According to the sensory evaluation, pectin-incorporated muffin was the best as it had obtained the highest sum of ranks for appearance, color, taste, after taste, and overall acceptability.

\section{Data Availability}

The data used to support the findings of this study are included in the article.

\section{Conflicts of Interest}

The authors declare that there are no conflicts of interest regarding the publication of this paper.

\section{Acknowledgments}

The authors would like to acknowledge the Department of Food Science and Technology, Faculty of Applied Sciences, University of Sri Jayewardenepura, and Agricultural Research Station, Department of Agriculture, Telijjawila, Sri Lanka, for its collaboration in the research activity. The authors appreciate the financial support from the University of Sri Jayewardenepura towards this research.

\section{References}

[1] T. Thompson, "Wheat starch, gliadin, and the gluten-free diet," Journal of the American Dietetic Association, vol. 101, no. 12, pp. 1456-1459, 2001.

[2] C. Dubé, A. Rostom, R. Sy et al., "The prevalence of celiac disease in average-risk and at-risk Western European populations: a systematic review," Gastroenterology, vol. 128, no. 4, pp. S57-S67, 2005.

[3] J. King, J. Jeong, F. Underwood et al., “A261 incidence of celiac disease is increasing over time: a systematic review and metaanalysis," Journal of the Canadian Association of Gastroenterology, vol. 2, Supplement_2, pp. 512-514, 2019.

[4] K. Mustalahti, S. Lohinierni, P. Laippala, P. Collin, and M. Maki, "Imrovement of the quality of life of silent celiac disease patients during the gluten-free diet warrants screening," Gastroenterology, vol. 118, no. 4, p. A369, 2000.

[5] J. Duggan, "Coeliac disease: the great imitator," Medical Journal of Australia, vol. 180, no. 10, pp. 524-526, 2004.

[6] G. D. Rangani, R. P. Mahaliyanaarachchi, P. Sivashankar, I. C. Hettiarachchi, and B. E. Bandara, "A study on consumption pattern \& awareness of underutilized fruits among urbanites within Maharagana DS division," Journal of Applied Microbiology, vol. 119, no. 3, p. 859, 2017.

[7] R. Abeynayake and R. Sivakanesan, "Effect of boiling on the antioxidant capacity of Dioscorea alata (Raja Ala) grown in Sri Lanka," Tropical Agricultural Research, vol. 26, no. 1, p. 109, 2015.

[8] H. F. Shang, H. C. Cheng, H. J. Liang, H. Y. Liu, S. Y. Liu, and W. C. Hou, "Immuostimulatory activities of yam tuber mucilages," Botanical Studies, vol. 48, pp. 63-70, 2007.

[9] Y. H. Liu, Y. S. Lin, D. Z. Liu et al., "Effects of different types of yam (Dioscorea alata) products on the blood pressure of spontaneously hypertensive rats," Bioscience Biotechnology and Biochemistry, vol. 73, no. 6, pp. 1371-1376, 2009.

[10] M. Belarmino and J. Gonzales, "Somatic embryogenesis and plant regeneration in purple food yam (Dioscorea alata L.)," Annals of Tropical Research, vol. 2, no. 30, pp. 22-33, 2008.

[11] T. Agbor-Egbe and S. Treche, "Evaluation of the chemical composition of Cameroonian yam germplasm," Journal of Food Composition and Analysis, vol. 8, no. 3, pp. 274-283, 1995.

[12] L. Pangyuan, "Effects of different cultivation methods on yield of purple yam," Science Discovery, vol. 4, no. 3, p. 173, 2016.

[13] R. Larief and A. Dirpan, "Purple yam flour (Dioscorea alata L.) processing effect on anthocyanin and antioxidant capacity in 
traditional cake "Bolu Cukke" making," in IOP Conference Series: Earth and Environmental Science, Bali, Indonesia, 2018.

[14] I. Demirkesen, G. Sumnu, S. Sahin, and M. Ozcan, "Erratum to: quality of gluten-free bread formulations baked in different ovens," Food and Bioprocess Technology, vol. 7, no. 2, pp. 619619, 2014.

[15] H. Herawati, "Hydrocolloids to the effects of gluten free bakery products," Journal of Physics: Conference Series, vol. 1295, article 012052, 2019.

[16] M. Gómez, F. Ronda, P. Caballero, C. A. Blanco, and C. M. Rosell, "Functionality of different hydrocolloids on the quality and shelf-life of yellow layer cakes," Food Hydrocolloids, vol. 21, no. 2, pp. 167-173, 2007.

[17] A. Yemenicioğlu, S. Farris, M. Turkyilmaz, and S. Gulec, "A review of current and future food applications of natural hydrocolloids," International Journal of Food Science \& Technology, vol. 55, no. 4, pp. 1389-1406, 2020.

[18] Z. Kohajdová, J. Karovičová, and S. Schmidt, "Significance of emulsifiers and hydrocolloids in bakery industry," Acta Chimica Slovaca, vol. 2, no. 1, 2009.

[19] B. Murray, E. Dickinson, C. Gransard, and I. Söderberg, "Effect of thickeners on the coalescence of protein-stabilized air bubbles undergoing a pressure drop," Food Hydrocolloids, vol. 20, no. 1, pp. 114-123, 2006.

[20] Q. Zhao, M. Zhao, B. Yang, and C. Cui, "Effect of xanthan gum on the physical properties and textural characteristics of whipped cream," Food Chemistry, vol. 116, no. 3, pp. 624628, 2009.

[21] P. Ribotta, G. Pérez, A. León, and M. Añón, "Effect of emulsifier and guar gum on micro structural, rheological and baking performance of frozen bread dough," Food Hydrocolloids, vol. 18, no. 2, pp. 305-313, 2004.

[22] A. Lazaridou, D. Duta, M. Papageorgiou, N. Belc, and C. Biliaderis, "Effects of hydrocolloids on dough rheology and bread quality parameters in gluten-free formulations," Journal of Food Engineering, vol. 79, no. 3, pp. 1033-1047, 2007.

[23] T. M. Bhaduri S and G. R. Navder KP, "Physical, textural and sensory characteristics of gluten free muffins prepared with Teff flour (Eragrostistef (ZUCC) Trotter)," Journal of Food Processing \& Technology, vol. 6, no. 9, 2015.

[24] M. Gómez, S. del Real, C. Rosell, F. Ronda, C. A. Blanco, and P. A. Caballero, "Functionality of different emulsifiers on the performance of breadmaking and wheat bread quality," European Food Research and Technology, vol. 219, no. 2, pp. 145150, 2004.

[25] G. Ahlborn, O. Pike, S. Hendrix, W. M. Hess, and C. S. Huber, "Sensory, mechanical, and microscopic evaluation of staling in low-protein and gluten-free breads," Cereal Chemistry Journal, vol. 82, no. 3, pp. 328-335, 2005.

[26] D. McCarthy, E. Gallagher, T. Gormley, T. Schober, and E. Arendt, "Application of response surface methodology in the development of gluten-free bread," Cereal Chemistry Journal, vol. 82, no. 5, pp. 609-615, 2005.

[27] AOAC International, “AOAC International," 2021, https:// www.aoac.org/.

[28] B. Broyart, G. Trystram, and A. Duquenoy, "Predicting colour kinetics during cracker baking," Journal of Food Engineering, vol. 35, no. 3, pp. 351-368, 1998.

[29] CT3 Texture Analyzer, “Ametek Brookfield,” https://www .brookfieldengineering.com/-/media/ametekbrookfield/ manuals/texture/ct3\%20manual\%20m08-372-f1116.pdf?.
[30] M. Ureta, D. Olivera, and V. Salvadori, "Quality attributes of muffins: effect of baking operative conditions," Food and Bioprocess Technology, vol. 7, no. 2, pp. 463-470, 2014.

[31] O. Radočaj and E. Dimić, "Valorization of wet okara, a valueadded functional ingredient, in a coconut-based baked snack," Cereal Chemistry Journal, vol. 90, no. 3, pp. 256-262, 2013.

[32] M. Lostie, "Study of sponge cake batter baking process. Part I: experimental data," Journal of Food Engineering, vol. 51, no. 2, pp. 131-137, 2002.

[33] D. Saha and S. Bhattacharya, "Characteristics of Gellan gum based food gels," Journal of Texture Studies, vol. 41, no. 4, pp. $459-471,2010$.

[34] A. Miyamoto and K. C. Chang, "Extraction and physicochemical characterization of pectin from sunflower head residues," Journal of Food Science, vol. 57, no. 6, pp. 1439-1443, 1992.

[35] M. Dogan, O. Toker, and M. Goksel, "Rheological behaviour of instant hot chocolate beverage: part 1. Optimization of the effect of different starches and gums," Food Biophysics, vol. 6, no. 4, pp. 512-518, 2011.

[36] S. Karaman, Y. Kesler, M. Goksel, M. Dogan, and A. Kayacier, "Rheological and some physicochemical properties of selected hydrocolloids and their interactions with guar gum: characterization using principal component analysis and viscous synergism index," International Journal of Food Properties, vol. 17, no. 8, pp. 1655-1667, 2014.

[37] Healthline, "7 benefits of purple yam (ube), and how it differs from taro," 2021, https://www.healthline.com/nutrition/ubepurple-yam\#TOC_TITLE_HDR_2.

[38] S. Adams, E. Paparozzi, and W. Stroup, "Comparison of chromometer readings and sensory evaluations on plant color and quality," HortScience, vol. 30, no. 4, pp. 891D-8891, 1995.

[39] S. Mundt and B. Wedzicha, "A kinetic model for browning in the baking of biscuits: effects of water activity and temperature," LWT - Food Science and Technology, vol. 40, no. 6, pp. 1078-1082, 2007.

[40] A. Torbica, M. Hadnađev, and T. Dapčević, "Rheological, textural and sensory properties of gluten-free bread formulations based on rice and buckwheat flour," Food Hydrocolloids, vol. 24, no. 6-7, pp. 626-632, 2010.

[41] U. Krupa, C. M. Rosell, J. Sadowska, and M. Soral-Śmietana, "Bean starch as ingredient for gluten-free bread," Journal of Food Processing and Preservation, vol. 34, pp. 501-518, 2010.

[42] H. Gambus, M. Sikora, and R. Ziobro, "The effect of composition of hydrocolloids on properties of gluten-free bread," ACTA Scientiarum Polonorum, vol. 6, no. 3, pp. 61-74, 2007.

[43] T. Funami, Y. Kataoka, T. Omoto, Y. Goto, I. Asai, and K. Nishinari, "Effects of non-ionic polysaccharides on the gelatinization and retrogradation behavior of wheat starch," Food Hydrocolloids, vol. 19, no. 1, pp. 1-13, 2005.

[44] D. Eidam, W. Kulicke, K. Kuhn, and R. Stute, "Formation of maize starch gels selectively regulated by the addition of hydrocolloids," Starch - Stärke, vol. 47, no. 10, pp. 378-384, 1995.

[45] E. Gimeno, C. Moraru, and J. Kokini, "Effect of xanthan gum and CMC on the structure and texture of corn flour pellets expanded by microwave heating," Cereal Chemistry Journal, vol. 81, no. 1, pp. 100-107, 2004.

[46] B. Urlacher and O. Noble, Thickening and Gelling Agents for Food, A. Imeson, Ed., Blackie Academic \& Professional, London, Chapter 13 edition, 1997. 